\title{
The impact of living arrangements and intergenerational support on the health status of older people in China: are rural residents disadvantaged compared to urban residents?
}

\author{
Yazhen Yang ${ }^{1 \star}$ (D), Maria Evandrou ${ }^{1,2,3}$ (D) and Athina Vlachantoni ${ }^{1,2,3}$ (D) \\ ${ }^{1}$ Department of Gerontology, University of Southampton, Southampton, UK, ${ }^{2}$ ESRC Centre for Population \\ Change, University of Southampton, Southampton, UK and ${ }^{3}$ Centre for Research on Ageing, University of \\ Southampton, Southampton, UK \\ ${ }^{*}$ Corresponding author. Email: yazhen.yang@soton.ac.uk
}

(Accepted 27 April 2021; first published online 2 June 2021)

\begin{abstract}
Research to-date has examined the impact of intergenerational support in terms of isolated types of support, or at one point in time, failing to provide strong evidence of the complex effect of support on older persons' wellbeing. Using the Harmonised China Health and Retirement Longitudinal Study (2011, 2013 and 2015), this paper investigates the impact of older people's living arrangements and intergenerational support provision/ receipt on their physical and psychological wellbeing, focusing on rural-urban differences. The results show that receiving economic support from one's adult children was a stronger predictor for higher life satisfaction among rural residents compared to urban residents, while grandchild care provision was an important determinant for poor life satisfaction only for urban residents. Having weekly in-person and distant contact with one's adult children reduced the risk of depression in both rural and urban residents. Older women were more likely than men to receive support and to have contact with adult children, but also to report poor functional status and depression. The paper shows that it is important to improve the level of public economic transfers and public social care towards vulnerable older people in rural areas, and more emphasis should be placed on improving the psychological wellbeing of urban older residents, such as with the early diagnosis of depression.
\end{abstract}

Keywords: intergenerational support; physical health; psychological health; living arrangements; hukou; rural; urban; China Health and Retirement Longitudinal Study (CHARLS)

\section{Introduction}

Population ageing is one of the most significant trends and challenges of the 21st century. The trend of population ageing is dramatic in Asia, which is spurred by a

(c) The Author(s), 2021. Published by Cambridge University Press. This is an Open Access article, distributed under the terms of the Creative Commons Attribution licence (http://creativecommons.org/licenses/by/4.0/), which permits unrestricted re-use, distribution, and reproduction in any medium, provided the original work is properly cited. 
tremendous industrialisation and urbanisation process (Chen et al., 2016). China is a unique context for studying population ageing, characterised by the largest absolute number of older people in the world, a massive rural to urban migration trend, and its Confucius culture and family-centred traditions (Ao et al., 2016; Ministry of Civil Affairs, 2018).

China has been an aged nation since 2000 (National Bureau of Statistics of the People's Republic of China (NBS), 2002). Approximately 250 million people were aged 60 or over by the end of 2018, which accounted for 17.9 per cent of the total population in China (NBS, 2019). Another characteristic of China lies in the remarkable rural and urban differences in terms of economic and cultural development, employment opportunities and public facilities (The Statistics Portal, 2015). Since the reform and opening-up policy in 1979, the urban areas of China have accumulated greater wealth, capital, innovative enterprises and public services, and have attracted a better-educated and -trained labour force than rural areas, as the former are influenced by higher levels of economic growth, and by a more enhanced process of social development and city strategy (Qiu et al., 2013).

\section{The unique Chinese context}

Prior to the formation of the People's Republic in 1949, China had a comparatively large average family size due to the traditional belief of 'the more children, the more blessings' (多子多福) formulated in its long history (Zeng, 1986). The informal care provided by family members such as one's spouse and children was the major source of social care support received by older people (Chen and Silverstein, 2000). However, nuclear households have replaced the dominant role of multigenerational households in contemporary China, influenced by a number of factors including a reduced fertility rate, modernisation and rural to urban migration (Zimmer and Kwong, 2003; Ren and Treiman, 2015). According to The Statistics Portal (2015), the average household size has reduced from 5.21 persons in 1931 to 2.97 in 2014.

Differences between urban and rural areas permeate the dominant types of family structure found in each context. Evidence from previous research showed decreases in the number of stem families and increases in the number of nuclear families and conjugal families in urban areas of China (Ma et al., 2011). By contrast, the number of nuclear families in rural areas has dropped significantly since the 1990s, with an increase in single-person households being observed (Ma et al., 2011). This mainly results from the massive out-migration of young adults from rural to urban areas (Giles et al., 2010). As the living arrangements and the relationship between intergenerational family members play an important role in the health and wellbeing of older people (Li et al., 2009; Zhang et al., 2014), urban and rural disparities in the family structure are key when examining the factors affecting the wellbeing of the older population in China.

\section{Understanding intergenerational support exchange}

As argued by international scholars, whether older people live together with their adult children can exert a complex impact on the intergenerational support 
exchanges within the households (e.g. Silverstein et al., 2006; Giles et al., 2010; Graham et al., 2015). Most research has suggested that an increase in geographical distance between generations has reduced the amount of informal care provided from adult children to their parents, in either western or eastern contexts (e.g. Hank, 2007; Lin and Yi, 2011). Consistent with this, in a recent study involving older people in both rural and urban areas of China, one's living arrangement was found to be the most important determinant among demographic factors in influencing informal care received by older Chinese people ( $\mathrm{Hu}$ and $\mathrm{Ma}, 2018$ ). Meanwhile, the out-migration of an adult child influences the intergenerational economic support provision bi-directionally (e.g. Taylor et al., 2003; Cong and Silverstein, 2011; Graham et al., 2015). For example, previous studies have shown that adult migrants sent large amounts of remittances back home to their parents (Taylor et al., 2003; Graham et al., 2015). In addition, older parents assisted their migrant children financially with transportation, relocation, training and start-up costs in the immigrant cities (Cong and Silverstein, 2011).

Previous research has found complex associations between the exchange of different types and directions of intergenerational support and physical and psychological health among older people (e.g. Silverstein et al., 2006; Li et al., 2009; Gruenewald and Seeman, 2011; Peng et al., 2019). For example, a longitudinal study based on three waves of data collected in the rural Anhui Province between 2001 and 2006 showed that an increase in the provision of economic support by older people to their adult children was significantly linked with an improvement in older people's subjective health, while the receipt of economic support by older parents from their adult children had a negative impact on the former's selfreported wellbeing (Li et al., 2009). In addition, an increase in the receipt of informal care by older people resulted in deterioration of the self-reported health among older men, while mutual psychological support exchange improved the selfreported health status of older women (Li et al., 2009).

To date, most of the existing evidence in terms of intergenerational support exchange and its impact on the health of older people in China has been based on cross-sectional analysis. Earlier research (Lee et al., 1994) showed that a rise in the amount of intergenerational support exchange (either upward or downward) increased the prevalence of depression among older people in Taiwan. The authors argued that older people who maintained a support exchange with their children experienced a sense of loss of independence in their later life, which resulted in their depressive symptoms. However, a more recent study using data from respondents in both rural and urban areas in China in 2000 showed that a lack of social support from one's adult children was significantly associated with depressive symptoms among older people (Chen et al., 2005). Based on data collected in the rural Anhui Province in 2001, Silverstein et al. (2006) also found that upward economic transfers received by older people reduced their depressive symptoms. A recent study by Luo et al. (2017) investigated the association between familial support receipt and older people's physical and psychological health in rural and urban China separately, and found that the physical health of older people in rural areas was positively associated with the economic support they received, while such association was not found in urban areas. Moreover, having contact with adult children was found to have a positive association with older people's psychological health in 
rural areas (measured by depressive symptoms), which was not found in the urban sample (Luo et al., 2017). However, based on the analysis of cross-sectional data collected in 2013, this study failed to provide strong evidence of the complex causal relationships between intergenerational support and older people's health. One possible reason for these conflicting results in terms of intergenerational support exchange and health among older people may be that the majority of studies were based on cross-sectional data, and were limited and influenced by the potential causality problem (Graham et al., 2015).

Prior studies have indicated possible associations between the living arrangements of older people, different aspects of intergenerational support exchange and their health status, however, it is important to explore such changes in greater detail and over time. Most research has included intergenerational support as an independent variable with a cross-sectional approach, which fails to explore the competing views on the changes in the flows of different types of intergenerational support exchange over time (Oxman and Hull, 1997; Chao, 2011). Another research gap of previous studies lies in that the provision of intergenerational support by older people, especially social and psychological support, is often neglected (Leung et al., 2007). In addition, although researchers admit rural and urban differences in understanding the flows of intergenerational support, most previous studies have focused on rural areas only, or treated the entire Chinese population as a whole (e.g. Giles et al., 2010; Chen et al., 2011; Ning and Wang, 2015). Given the existing evidence on rural-urban differentials in other areas (e.g. Chen et al., 2005; Qiu et al., 2013; Luo et al., 2017), it is important to distinguish and compare the exchange of intergenerational support in rural and urban areas with a longitudinal approach. Finally, the effect of intergenerational support exchange on older people's physical health status has been rarely discussed in previous literature (Gruenewald and Seeman, 2011). This paper aims to fill such gaps by investigating the changes in the flows of intergenerational economic, social and psychological support in both upward and downward directions, which is unique to-date to our knowledge. It also explores the causal factors for such changes, and disentangles the impact of the changes on both the physical and psychological health of the Chinese older population between rural and urban areas.

\section{Theoretical framework}

The theoretical framework of this study is provided in Figure 1. Based on previous literature, this paper combines elements from the modernisation and ageing theory, the economics of labour migration theory and the modified extended family model for a more comprehensive understanding of the changes in intergenerational support exchanges (Litwak, 1960; Cowgill, 1972; Greenwell and Bengtson, 1997; Stark and Bloom, 1985).

The modernisation and ageing theory provides explanations for the decrease in economic support and informal care provided to older parents in modern society (Cowgill, 1972). The major aspects of the theory are parent-child geographic separation and increasing individualism among children (Aboderin, 2004). On the one hand, living far away from one's parents can result in a lower likelihood of exchanging social support/informal care between generations (Guo et al., 2009). On the other hand, new family structures and living arrangements result in familism 


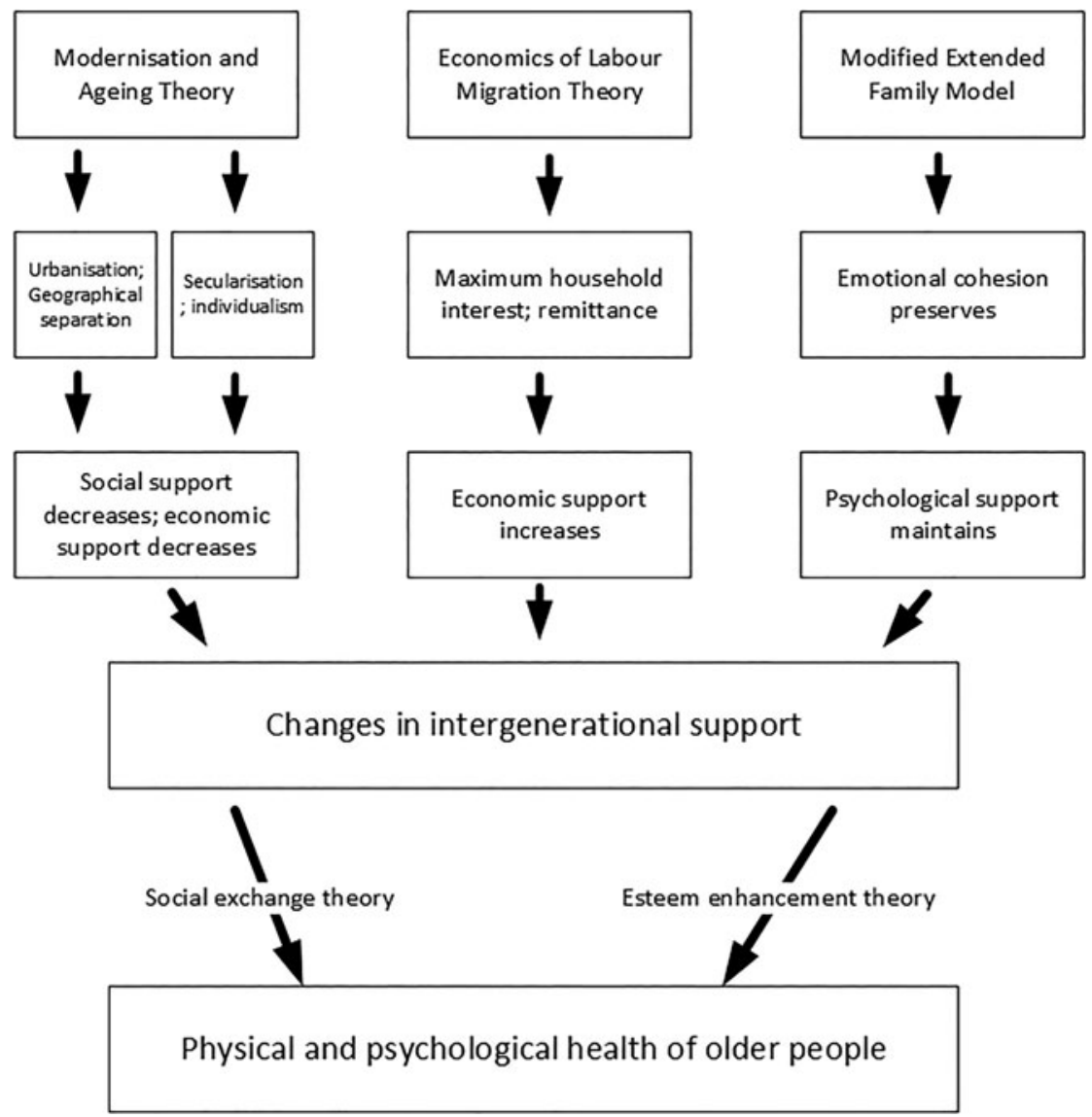

Figure 1. Theoretical framework for understanding changes in intergenerational support and the health of older people.

decreasing and individualism increasing, which can lead to the decreasing exchange of economic and social support (Guo et al., 2009).

The economics of labour migration theory provides explanations for the association between children's out-migration and the increase in the exchange of intergenerational economic support. The theory views migration as a household decision jointly made by movers and stayers in order to pursue maximum household benefits (Stark and Bloom, 1985). Parents provide economic support to their children while they settle down in the immigrant cities; at a later point, remittances are provided from the migrants to their parents left behind (Foster and Rosenzweig, 2001).

The modified extended family model posits that with advanced transportation and communication, extended family relations and psychological cohesion between family members can be upheld over great geographical distance in the modern society (Litwak, 1960; Bengtson et al., 2002). Influenced by the Confucius culture and values of filial piety, children living far away from their parents still provide upward economic and psychological support (Zhang et al., 2014). 
Consequently, the provision of intergenerational support exerts an impact on the health status of older people (Zhang et al., 2014), which can be explained by the social exchange theory and esteem enhancement theory (Chen and Jordan, 2018; Peng et al., 2019). The social exchange theory holds that people maximise benefits and minimise losses in relationships with others, therefore they will have better health when they receive support from others (Blau, 1964). The theory of esteem enhancement demonstrates that providing support to others improves the provider's wellbeing by enhancing the feeling of usefulness and self-worth (Batson and Powell, 1998). Elements of all these theories are useful in understanding the complex topic of changing living arrangements, intergenerational support exchanges and their impact on older people's wellbeing.

The following research questions are addressed by conducting statistical analyses based on the Harmonised China Health and Retirement Longitudinal Study (CHARLS) data in 2011, 2013 and 2015.

(1) What is the extent of the intergenerational support (economic, social, psychological and two directions of flow) in rural and urban areas of China today?

(2) To what extent have the flows of support in rural and urban areas of China changed over time?

(3) How have changes in the living arrangements with children impacted upon the change in intergenerational support exchange?

(4) How have changes in the intergenerational support exchange within Chinese families impacted upon the physical and psychological wellbeing of older people?

\section{Methods}

\section{Data and sample}

The CHARLS dataset is a nationally representative panel survey containing rich information about Chinese residents aged 45 or older from 28 provinces in China, which includes respondents from both rural villages and urban communities (Beaumaster et al., 2018). The data were firstly collected in 2011 and the sample has been refreshed at each of the following waves (Beaumaster et al., 2018). The dataset includes ten main modules, incorporating the demographic background data, family, health status and functioning data, work, retirement and pensions, and income data, etc. (Beaumaster et al., 2018). The dataset has an initial sample of 10,258 households and 17,500 individuals in 2011 (Wave 1), and the respondents were followed up every two years in 2013 (Wave 2) and 2015 (Wave 4) with a sample size of 18,612 and 21,097 respectively, with about 77 per cent of participants in 2011 responding at all three waves. The Wave 3 data (life history) was not included in the analyses due to the lack of information about intergenerational support exchange.

Due to a relatively high proportion of missing data in terms of the respondents' exchange of intergenerational support (about 40\%), the survey sample was reduced prior to further analysis. The analytical sample for the longitudinal analysis was 6,751 respondents who had a valid answer in all types of intergenerational support exchanges at all three waves. This study used the longitudinal weight at the 
individual level for the descriptive analyses (Chien et al., 2017). The longitudinal weight was calculated from the baseline weights with the construction of an inverse probability weighting factor based on a logit regression of whether a respondent participated in the following wave conditional on the participation in the baseline (CHARLS, 2015).

\section{Measures}

Intergenerational support

The main variables used to measure the exchanges of intergenerational support include economic and social support provided bi-directionally and weekly contact between generations. Patterns of intergenerational exchange are complicated and can be measured in a number of ways. The CHARLS dataset provides two measures for the exchange of intergenerational economic support: one is binary, asking whether the respondents or their spouse provided/received economic support to/ from their children/grandchildren in the previous year using separate questions, ${ }^{1}$ and the other is continuous, which is the amount of intergenerational monetary transfers in the previous year. As a high missing rate (about 70\%) was found for the amount of economic transfers in the original CHARLS datasets, this variable was only used in the descriptive analysis for understanding the level of intergenerational economic transfers in China (see Table S1 in the online supplementary material), and was omitted in the longitudinal analysis to minimise bias (Jiang et al., 2013).

Intergenerational social support in this study refers to the within-family care and support received and provided by older people. Upward social support is measured as 'whether older people obtain help from children with at least one of the (instrumental) activities of daily living' (Lei et al., 2015). This measure has been conceptualised as informal care in other research (e.g. Hu and Ma, 2018; Falkingham et al., 2020), hence the terms 'social support' and 'informal care' are used interchangeably in this study. The CHARLS data do not contain information about the social support provided from respondents to their adult children. This study uses grandchild caring as a proxy to examine the downward social support provided by older people or their spouse, with this approach having been utilised in previous research (Chen et al., 2011; Falkingham et al., 2020).

Some research examining intergenerational support provision has used social contact frequency as a proxy for the provision of psychological support (e.g. Oxman and Hull, 1997; Gruijters, 2017). In this current study, the exchange of intergenerational psychological support is reflected by the weekly in-person and distant contact (by either phone, mail or email) between respondents and their adult children. As all respondents co-residing with their children were assumed to see their children on a weekly basis, it would be biased to examine the association between living together with an adult child and having weekly in-person contact. Therefore, this study uses living nearby with an adult child as the main predictor in order to estimate the determinants of having intergenerational in-person and distant contact (Gruijters, 2017).

\section{Health outcomes}

A number of health measures, including physical and psychological approaches, are used to assess respondents' health status. These are the respondents' self-rated 
health, activities of daily living (ADLs) and instrumental activities of daily living (IADLs), functional status, life satisfaction and depression status. The original question on self-rated health was measured by a self-report of 'excellent, very good, good, fair or poor health'. The five-category answers were recoded and reduced to three categories $(1=$ poor, $2=$ fair, $3=$ good $)$ in order to increase the number of cases in each category.

The concepts of ADLs (Katz et al., 1963; Hartigan, 2007) and IADLs (Lawton and Brody, 1969; Graf, 2008) were used to measure the respondents' functional status in this study. A total score was created to summarise the respondents' difficulty with six items of ADLs and five items of IADLs. Having difficulty in each of the tasks added one point to the respondents' dependence score. For the ADL scoring, a respondent who scored between 4 and 6 was categorised as having a severe functional impairment, a score between 1 and 3 reflected a moderate functional impairment and a score of 0 suggested full functional status (Hartigan, 2007). For the IADL scoring, a respondent who scored between 3 and 5 was categorised as having a severe functional impairment, 1 or 2 represented a moderate functional impairment and a score of 0 indicated full functional status (Graf, 2008).

The information about life satisfaction was collected by a question with five levels of answers: $1=$ completely satisfied, $2=$ very satisfied, $3=$ somewhat satisfied, $4=$ not very satisfied and $5=$ not at all satisfied. This was also recoded and reduced to a variable with three categories: $1=$ poor, $2=$ fair and $3=$ good life satisfaction. The information on the depressive symptoms of respondents was collected using the ten-item Center for Epidemiologic Studies Depression Scale (CES-D 10) (Radloff, 1977). The total score was calculated using the sum of the ten items, ranging between 0 and 30. Similar to previous research (e.g. Cheng and Chan, 2008; $\mathrm{Ni}$ et al., 2017), this study uses 10 as a cut-off point, with respondents having a depression score of more than 10 being regarded as having depressive symptoms.

\section{Living arrangements}

In line with previous research, co-residence was used as a proxy to measure migration (Xie and Zhu, 2009; Giles et al., 2010). Therefore, 'whether the respondents co-reside with any child' $(1=$ yes, $0=$ no) was used to assess the adult child's outmigration. Living nearby refers to respondents living in the same household, community, village, town or city with their adult children $(1=$ yes, $0=$ no), and was used in the models with intergenerational contact as dependent variables.

\section{Hukou status}

The hukou household registration system identifies and registers Chinese individuals by their residential and administrative locations (urban versus rural). The respondents' hukou status was used to assess whether older people reside in rural or urban areas.

\section{Covariates}

There were two types of covariates, which were time-varying variables such as current marital status, involvement in paid work and individual earnings; and timeconstant variables including gender, age, ${ }^{2}$ educational attainment, the number of children alive and the number of chronic illnesses (Yang et al., 2016). Variables 
which do not show sufficient variation between waves, including one's education level, the number of children alive and the number of chronic illnesses, were regarded as time-constant factors in the analysis (Allison, 2009).

\section{Analytical approach}

Using the software of Stata V.16 (StataCorp, 2019), this study employs a hybrid method combining fixed and random effects, which can yield fixed-effects estimates for time-variant predictors and random-effects estimates for time-constant variables (Allison, 2009). Fixed-effects models are useful for controlling for the impact of unobserved permanent characteristics in a longitudinal study (Croezen et al., 2015). However, they fail to assess the effects of time-invariant variables, such as gender and educational attainment in this study. The use of random-effects models can help provide estimates for time-constant variables.

In the hybrid method, the time-varying predictors are transformed into deviations from their person-specific means, which helps to estimate the fixed-effects model of the time-variant variables (Allison, 2009; Schunck, 2013). In addition, time-invariant predictors and variables that are the person-specific means for the time-varying variables (which are also time-invariant) are also included in the hybrid model. Finally, a random-effects model is used to estimate the standard errors, which reflects the dependence among the multiple observations for each person (Allison, 2009; Schunck, 2013).

Different methods were used for the binary and categorical dependent variables in this study. For binary dependent variables (e.g. the receipt of economic support), a hybrid logistic model was implemented to assess the impact of the changes in the co-residence status with adult children upon the receipt of economic support (Allison, 2009). Equation 1 illustrates an example of such a model (Diggle, 2002; Rabe-Hesketh and Skrondal, 2008; Allison, 2009):

$$
\log \left(\frac{P_{i t}}{1-P_{i t}}\right)=\mu_{t}+\alpha_{1} R_{i t}+\alpha_{2} X_{i t}+\alpha_{3} Z_{i}+\gamma_{i}, t=1,2, \ldots, T
$$

where $i$ stands for the respondent; $t$ represents the year when the respondent was surveyed and $P_{i t}$ is the probability that the dependent variable (respondents receiving economic support from adult children) is equal to 1 . $R_{i t}$ stands for the co-residence status with adult children $(1=$ yes, $0=$ no $)$ and $X_{i t}$ is a vector of timevariant factors, including whether the respondents have children living nearby and other time-varying characteristics of the respondents (marital status, work status and individual income) (Cong and Silverstein, 2011). $Z_{i}$ is a vector of time-invariant predictors, such as the age, gender, hukou and education status of respondents (Huang et al., 2016; Oliveira, 2016). Finally, $\gamma_{i}$ represents the collective effects of all unobserved variables which are constant over time.

For dependent variables with more than two categories (e.g. life satisfaction), the conventional Maximum Likelihood Estimation with robust standard errors was applied in the model, in order to correct for any independence in the repeated observations for each individual (Allison, 2009). For example, the model of using respondents' life satisfaction as a dependent variable, and changes in the proportion 
of respondents receiving upward economic support as an independent variable, can be written as

$$
\log \left(\frac{F_{i j t}}{1-F_{i j t}}\right)=\mu_{t j}+\beta_{1} S_{i t}+\beta_{2} X_{i t}+\beta_{3} Z_{i}+\alpha_{i}, j=1, \ldots, J-1
$$

where $F_{i j t}=\sum_{m=j}^{J} P_{i m t}$ is the cumulative probability of being in category $j$ or higher on the life satisfaction of respondent $i$ at time $t$. $S_{i t}$ stands for the proportion of respondents receiving upward economic support $\left(1=\right.$ yes, $0=$ no); $X_{i t}$ and $Z_{i}$ are vectors that have the same representations as in Equation 1. $\beta$ is the regression parameter and $\alpha_{i}$ represents the combined effects of all unobserved constant variables.

The above models may be challenged with the reverse causality concept (Graham et al., 2015; Liu and Zhang, 2017; Zheng and Zheng, 2017). In order to minimise the potential impact of reverse causality, this study implements hybrid models with lagged (by two years) independent variables in order to examine whether changes in the independent variable between Waves 1 and 2 are associated with changes in the dependent variable between Waves 2 and 4 (Allison, 2009; Croezen et al., 2015). Lagged models are less susceptible to reverse causality, because they relate current changes in the independent variables to subsequent changes in the dependent variable. The implementation of a lagged hybrid method combining fixed- and random-effects models adds strength and robustness to the statistical analyses in this study.

\section{Results}

Table 1 shows the descriptive analysis of the characteristics of respondents in all three waves based on the longitudinal sample. The analytical samples for the rural areas were 5,868,5,827 and 5,824 in Waves 1, 2 and 4, respectively, and for the urban areas they were 883, 924 and 927, respectively. The number of respondents with rural hukou was much larger than those with urban hukou because there were more older residents with rural hukou than those with urban hukou in China (NBS, 2019). The average age of the respondents in rural areas was slightly lower than that in urban areas at all three waves. There were slightly more female (about 54\%) than male respondents in the rural sample, and more male (about $53 \%)$ than female respondents in the urban sample. The majority of respondents were married or partnered in each of the three waves. Older people in rural areas were more likely to co-reside with their adult children compared to their urban counterparts, whilst the proportion of older people living near adult children did not show significant differences.

\section{Exchange of intergenerational support}

Figure 2 shows the changes in the proportion of older people having intergenerational economic and social support exchange and weekly contact with their adult children/grandchildren by their hukou status. The exact statistics are presented in 
Table 1. Descriptive analysis of the characteristics of respondents, by hukou status (2011, 2013 and 2015)

\begin{tabular}{|c|c|c|c|c|c|c|c|c|c|}
\hline \multirow[b]{2}{*}{ Characteristics of respondents } & \multicolumn{3}{|c|}{ Wave 1} & \multicolumn{3}{|c|}{ Wave 2} & \multicolumn{3}{|c|}{ Wave 3} \\
\hline & $\begin{array}{l}\text { Rural } \\
\text { hukou }\end{array}$ & $\begin{array}{l}\text { Urban } \\
\text { hukou }\end{array}$ & $\begin{array}{c}\text { Significance } \\
\left(\chi^{2} / t \text {-test }\right)\end{array}$ & $\begin{array}{l}\text { Rural } \\
\text { hukou }\end{array}$ & $\begin{array}{l}\text { Urban } \\
\text { hukou }\end{array}$ & $\begin{array}{c}\text { Significance } \\
\left(\chi^{2} / t \text {-test }\right)\end{array}$ & $\begin{array}{l}\text { Rural } \\
\text { hukou }\end{array}$ & $\begin{array}{l}\text { Urban } \\
\text { hukou }\end{array}$ & $\begin{array}{c}\text { Significance } \\
\left(\chi^{2} / t \text {-test }\right)\end{array}$ \\
\hline $\mathrm{N}$ & 5,868 & 883 & & 5,827 & 924 & & 5,824 & 927 & \\
\hline Age: & & & 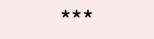 & & & 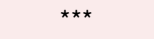 & & & $\star \star \star *$ \\
\hline Mean & 58.4 & 60.7 & & 60.3 & 62.5 & & 62.3 & 64.3 & \\
\hline \multicolumn{10}{|l|}{ Range (\%): } \\
\hline $45-59$ & 59.5 & 48.3 & & 47.9 & 35.6 & & 36.2 & 24.0 & \\
\hline $60-74$ & 37.2 & 48.0 & & 47.1 & 57.7 & & 56.6 & 66.6 & \\
\hline 75 or over & 3.3 & 3.7 & & 5.0 & 6.7 & & 7.2 & 9.4 & \\
\hline Missing & 0 & 0 & & 0 & 0 & & 0 & 0 & \\
\hline Gender (\%): & & & $\star \star \star$ & & & $\star \star \star *$ & & & $\star \star \star$ \\
\hline Male & 46.3 & 52.8 & & 46.2 & 54.1 & & 46.2 & 53.2 & \\
\hline Female & 53.7 & 47.2 & & 53.8 & 45.9 & & 53.8 & 46.8 & \\
\hline Missing & 0 & 0 & & 0 & 0 & & 0 & 0 & \\
\hline Education level (\%): & & & $\star \star \star$ & & & $\star \star \star ~$ & & & 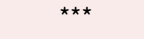 \\
\hline Less than lower secondary & 94.7 & 73.8 & & 95.1 & 73.5 & & 95.0 & 72.6 & \\
\hline Upper secondary and vocational training & 5.1 & 20.7 & & 4.8 & 20.8 & & 4.9 & 21.3 & \\
\hline Tertiary & 0.2 & 5.5 & & 0.1 & 5.7 & & 0.1 & 6.1 & \\
\hline Missing & 0 & 0.1 & & 0 & 0.1 & & 0 & 0 & \\
\hline Marital status (\%): & & & $* * *$ & & & $\star \star \star$ & & & $\star \star \star$ \\
\hline Married/partnered & 90.7 & 91.2 & & 89.5 & 88.6 & & 87.2 & 88.1 & \\
\hline Divorced/separated & 0.8 & 1.8 & & 0.4 & 1.6 & & 0.3 & 1.5 & \\
\hline
\end{tabular}


Table 1. (Continued.)

\begin{tabular}{|c|c|c|c|c|c|c|c|c|c|}
\hline \multirow[t]{2}{*}{ Characteristics of respondents } & \multicolumn{3}{|c|}{ Wave 1} & \multicolumn{3}{|c|}{ Wave 2} & \multicolumn{3}{|c|}{ Wave 3} \\
\hline & $\begin{array}{l}\text { Rural } \\
\text { hukou }\end{array}$ & $\begin{array}{l}\text { Urban } \\
\text { hukou }\end{array}$ & $\begin{array}{c}\text { Significance } \\
\left(\chi^{2} / t \text {-test }\right)\end{array}$ & $\begin{array}{l}\text { Rural } \\
\text { hukou }\end{array}$ & $\begin{array}{l}\text { Urban } \\
\text { hukou }\end{array}$ & $\begin{array}{c}\text { Significance } \\
\left(\chi^{2} / t \text {-test }\right)\end{array}$ & $\begin{array}{l}\text { Rural } \\
\text { hukou }\end{array}$ & $\begin{array}{l}\text { Urban } \\
\text { hukou }\end{array}$ & $\begin{array}{c}\text { Significance } \\
\left(\chi^{2} / t \text {-test }\right)\end{array}$ \\
\hline Widowed & 8.4 & 7.0 & & 10.0 & 9.8 & & 12.3 & 10.3 & \\
\hline Single never married & 0.1 & 0 & & 0.1 & 0 & & 0.2 & 0.1 & \\
\hline Missing & 0 & 0 & & 0 & 0 & & 0 & 0 & \\
\hline Work status (\%): & & & $\star \star \star *$ & & & $\star \star \star *$ & & & $\star \star \star *$ \\
\hline Did not work last year & 22.1 & 64.0 & & 25.6 & 62.6 & & 30.7 & 63.0 & \\
\hline Worked last year & 77.7 & 35.6 & & 73.8 & 36.8 & & 68.9 & 35.8 & \\
\hline Missing & 0.2 & 0.4 & & 0.6 & 0.6 & & 0.4 & 1.2 & \\
\hline Individual income: ${ }^{1}$ & & & $\star \star \star *$ & & & $\star \star \star *$ & & & $\star \star \star *$ \\
\hline Mean & 2,428 & 7,213 & & 2,840 & 5,031 & & 2,057 & 4,604 & \\
\hline Missing & 0 & 0 & & 0 & 0 & & 0 & 0 & \\
\hline Live with at least one adult child (\%): & & & $\star \star \star *$ & & & $\star \star \star *$ & & & $\star \star \star *$ \\
\hline No & 37.9 & 46.4 & & 45.9 & 52.3 & & 44.2 & 52.0 & \\
\hline Yes & 62.1 & 53.6 & & 54.0 & 47.7 & & 55.8 & 48.0 & \\
\hline Missing & 0 & 0 & & 0.1 & 0 & & 0 & 0 & \\
\hline Live nearby at least one adult child (\%): & & & $\star \star \star$ & & & $\star \star \star *$ & & & $\star \star * *$ \\
\hline No & 7.4 & 4.9 & & 9.7 & 7.9 & & 10.7 & 12.1 & \\
\hline Yes & 92.6 & 95.1 & & 90.3 & 92.1 & & 88.4 & 87.2 & \\
\hline Missing & 0 & 0 & & 0 & 0 & & 0.9 & 0.7 & \\
\hline
\end{tabular}

Notes: Only respondents who had a valid answer to intergenerational support at all three waves were included. Unit of analysis: RMB (2015: 1 GBP $=9.616$ CNY).

Significance level: ${ }^{* \star} p<0.001$ (showing that the characteristics of respondents significantly differ between the rural and urban sample at $p<0.001$ based on the $\chi^{2} / t$-test).

Source: Authors' analysis of the China Health and Retirement Longitudinal Study (CHARLS) data, weighted percentage, unweighted sample count. 


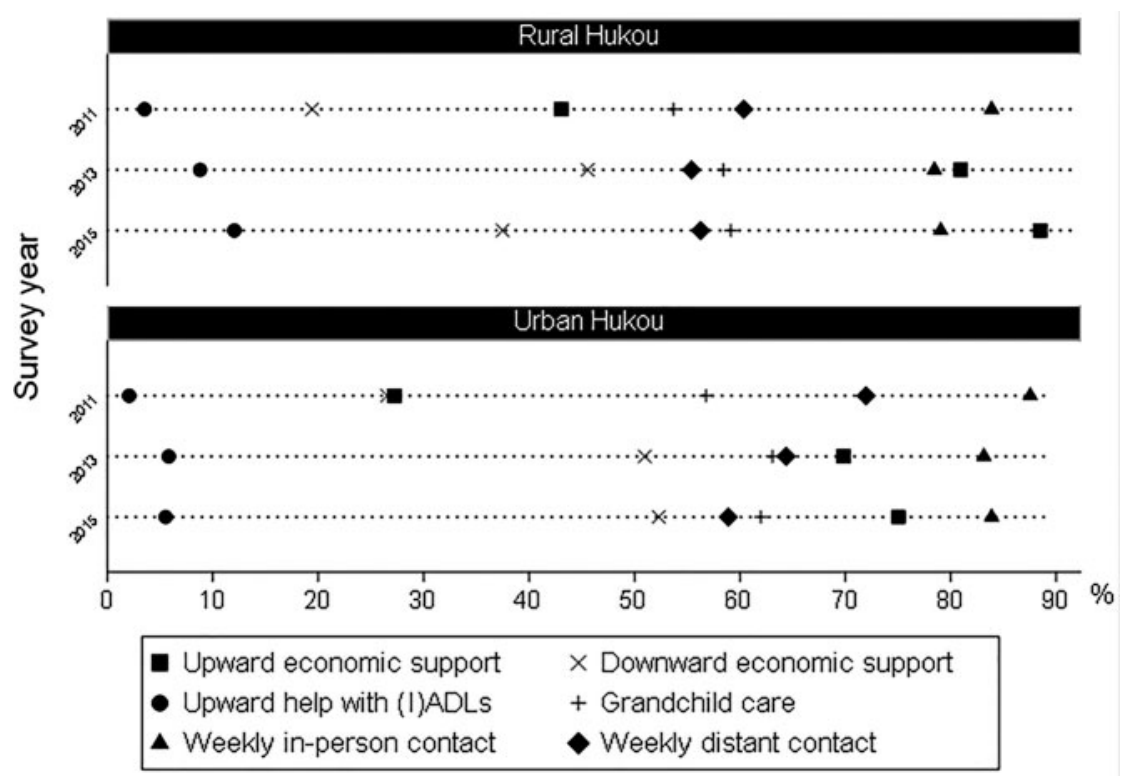

Figure 2. Mean percentage of respondents experiencing intergenerational support, by hukou status (2011, 2013 and 2015).

Note: (I)ADL: (instrumental) activities of daily living.

Table S1 in the online supplementary material. A higher proportion of older people in rural areas reported the receipt of economic support from their adult children compared to their urban counterparts (see squares in Figure 2), which increased from 42 per cent in 2011 to 79 per cent in 2013 and 86 per cent in 2015 (compared to $27 \%$ in $2011,70 \%$ in 2013 and $75 \%$ in 2015 in urban areas). By contrast, a higher proportion of older people in urban areas provided economic support to their adult children/grandchildren compared to those in rural areas (urban: 27\% in 2011, 51\% in 2013 and 52\% in 2015, compared to rural: 19\% in 2011, 44\% in 2013 and 36\% in 2015) (see Xs in Figure 2). The differences in the proportion of older people having intergenerational economic support exchange between rural and urban areas were statistically significant, which indicated that older people in rural areas were more dependent on their adult children for economic support compared to their urban counterparts. A higher proportion of older people in urban areas were entitled to decent employment, pensions and had better economic status than their rural counterparts, therefore, they were less likely to receive economic transfers from their adult children and instead more likely to provide such transfers to them.

Interestingly, although a higher proportion of older people in rural areas received economic support from their adult children, the average amount of such support was lower compared to their urban counterparts (see more in Table S1 in the online supplementary material). Meanwhile, the average amount of economic support provided by older people was higher in urban areas compared to rural areas. In addition, the average amount of economic transfers from older people to adult children/grandchildren was lower than that provided in the opposite 
direction (from adult children/grandchildren to older people). The results were consistent with previous research showing the traditional mainstream of upward economic support in China ( $\mathrm{Du}$ and $\mathrm{Wu}, 2006$; Wang and Chen, 2017), and the larger amount of intergenerational economic transfers exchanged in urban areas can be explained by the better economic status of residents in urban areas.

As shown in Figure 2, compared to older people in urban areas, respondents in rural areas had a higher probability of receiving informal care from their adult children (see circles in Figure 2). This may be associated with the higher proportion of older people living together with their adult child in rural areas (see Table 1), which will be further examined later in this paper. By contrast, older people in urban areas were slightly more likely to provide grandchild care and to have weekly in-person/ distant contact with their adult children compared to their rural counterparts (see pluses, triangles and diamonds in Figure 2). A possible reason is that younger adults in urban areas were more likely to engage with formal work compared to their rural counterparts, and their parents assisted with child care due to their children participating in the labour force. Furthermore, older people were more likely to have economic and social support exchange with their adult children in 2013 and 2015 compared to 2011, regardless of their hukou status. However, the proportion of respondents having intergenerational weekly in-person and distant contact declined in 2013 and 2015 compared to 2011 in both rural and urban regions.

\section{Understanding the changes in intergenerational support exchange}

Following the descriptive analyses of the intergenerational economic, social support and weekly contact, this section examines the associations between older people's living arrangements with adult children and the exchange of intergenerational economic, social and psychological support. Models 1-12 in Table S2 (in the online supplementary material) estimate the influence of living together/living nearby with an adult child between Waves 1 and 2 on older people's receipt/provision of economic, social and psychological support between Waves 2 and 4 in rural and urban areas, respectively.

Figure 3 illustrates the results based on Models 1-12 by presenting the coefficient plot (for relevant statistics in detail, see Table S2 in the online supplementary material). The results show that the direction of the association between the living arrangements with adult children and the exchange of economic and social support was similar for older people in rural and urban areas (Figure 3a). The odds of receiving upward economic support reduced for respondents who experienced a change from non-co-residing with any of their adult children to co-residing with at least one child in both rural and urban areas. The results provide further evidence to previous studies which found that older people not co-residing with adult children had a higher likelihood of receiving economic transfers/remittances provided by adult children compared to those who co-resided with at least one adult child (Cong and Silverstein, 2011; Graham et al., 2015).

In addition, the odds of respondents providing economic support to their adult children/grandchildren reduced when they experienced a change from a non-co-residence to a co-residence status with adult children in both rural and urban areas. There may be two reasons for this. First, a large number of migrants 
(a)

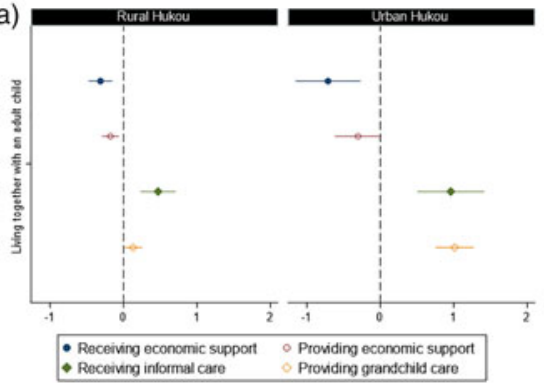

(b)

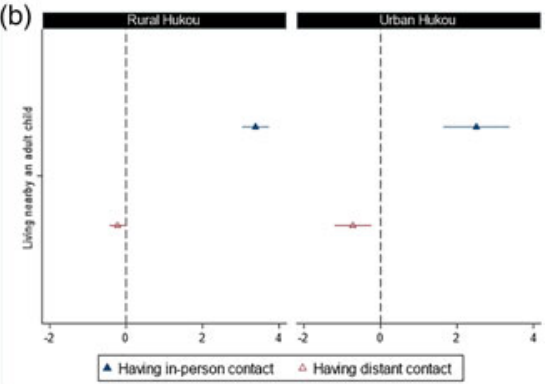

Figure 3. Influence of living arrangements on the exchange of intergenerational support among older people in rural and urban areas (2011, 2013 and 2015).

Note: Covariates such as the age, gender, marital status, educational attainment, whether currently working, individual income, the number of chronic illnesses and children were included in the models, the results of which were significant but omitted in the figure for the clarity of result visualisation.

Source: Authors' analysis of the China Health and Retirement Longitudinal Study (CHARLS) data.

who work in urban areas would return home when having accumulated a certain amount of wealth (Tang and Feng, 2015). In such cases, older people do not need to provide economic support to their adult children as the children have sufficient financial resources. Second, migrant adult children may return home because of the care needed by their older parents. This often happens when older people are suffering from serious illnesses, mobility difficulties or are hospitalised (Giles and $\mathrm{Mu}, 2007$ ). Older people who are severely ill and demand care from their adult children are not likely to provide economic transfers to their adult children.

Figure $3 \mathrm{a}$ also shows the associations between co-residence with adult children and the receipt/provision of social support. The results suggest that a non-co-residence to co-residence (with adult children) transition was associated with an increase in the odds of receiving support with ADLs and IADLs from adult children, for respondents in both rural and urban areas. Moreover, for both rural and urban areas, the odds of grandchild-caring provision rose if older respondents experienced a change from non-co-residence to co-residence with adult children. To sum up, respondents who had at least one adult child returning home were more likely to receive support with their ADLs and IADLs, and to provide grandchild care compared to respondents who had no co-resident adult children. This association was similar for older people in rural and urban areas. The results from this current study, to some extent, support the notion of reduced social care received by older people as denoted by the modernisation and ageing theory, and further indicate the importance of encouraging younger Chinese adults to co-reside with or live closer to their older parents. As elaborated earlier, intergenerational co-residence can largely facilitate the process of social support provided from adult children to their older parents (e.g. Silverstein et al., 2006; Guo et al., 2009).

The results further suggest that a change from not living nearby any adult children to living nearby at least one adult child was associated with an increase in the odds of having weekly in-person contact with their adult children, for respondents 
in both rural and urban areas (see solid triangles in Figure 3b). In addition, Figure $3 \mathrm{~b}$ shows that in both rural and urban areas, the odds of having weekly distant contact with their adult children reduced among older respondents if they had at least one adult child living closer to them. As mentioned in the Methods section, whether respondents had weekly distant contact with their adult children was only asked of those who had at least one non-co-resident child. Therefore, the result relating to having weekly distant contact may be underestimated. In sum, respondents in both rural and urban areas who had at least one adult child moving geographically closer to them were more likely to have weekly in-person contact with their adult children, and less likely to have weekly distant contact with their children if they moved closer.

Existing literature seems to convey an idea that the out-migration of adult children has exerted a negative influence on maintaining frequent contact, and possibly even worse, the psychological ties between generations within Chinese families (Chou and Chi, 2000; Hank, 2007). This current study supports evidence that people who lived near their adult children were more likely to have weekly in-person contact with them compared to those who did not live close to their adult children. However, this current study also challenges the idea with an additional piece of evidence, showing that respondents who lived nearby their adult children were less likely to have weekly distant contact with them compared to those who did not have any adult child living nearby. Therefore, it can be assumed from the results that as adult children are living further away, the traditional ways of in-person contact are being replaced by distant contact via phone calls, texts and emails.

\section{Understanding intergenerational support and older people's health}

The direction and strength of the associations between different types of intergenerational support exchange and the health condition of older people vary. Figure 4 presents the results of the four models examining the influence of intergenerational support exchange on the self-rated health, ADL functional status, life satisfaction and depression status of older people. The figure does not show the modelling results of older people having difficulties with their IADL functional status, as these were similar to the results of having ADL functional difficulties. The model estimation includes covariates such as the age, gender, marital status, educational attainment, whether currently working, individual income, co-residing with at least one adult child, the number of chronic illnesses and children, however, these were omitted in Figure 4 for the clarity of result visualisation.

Figure 4a shows that for older people in rural areas, the odds of reporting poor ADL functional status increased with the receipt of economic support from adult children; and the odds of having a low life satisfaction reduced for those who received such support. However, receiving economic transfers from adult children did not have a significant association with the health status of older people in urban areas. The findings suggest that receiving upward economic support is beneficial for older people's life satisfaction in rural areas, which highlights the importance of additional attention paid to the health and wellbeing of the segment of the population who lack economic transfers with their adult children. 
Independent variables

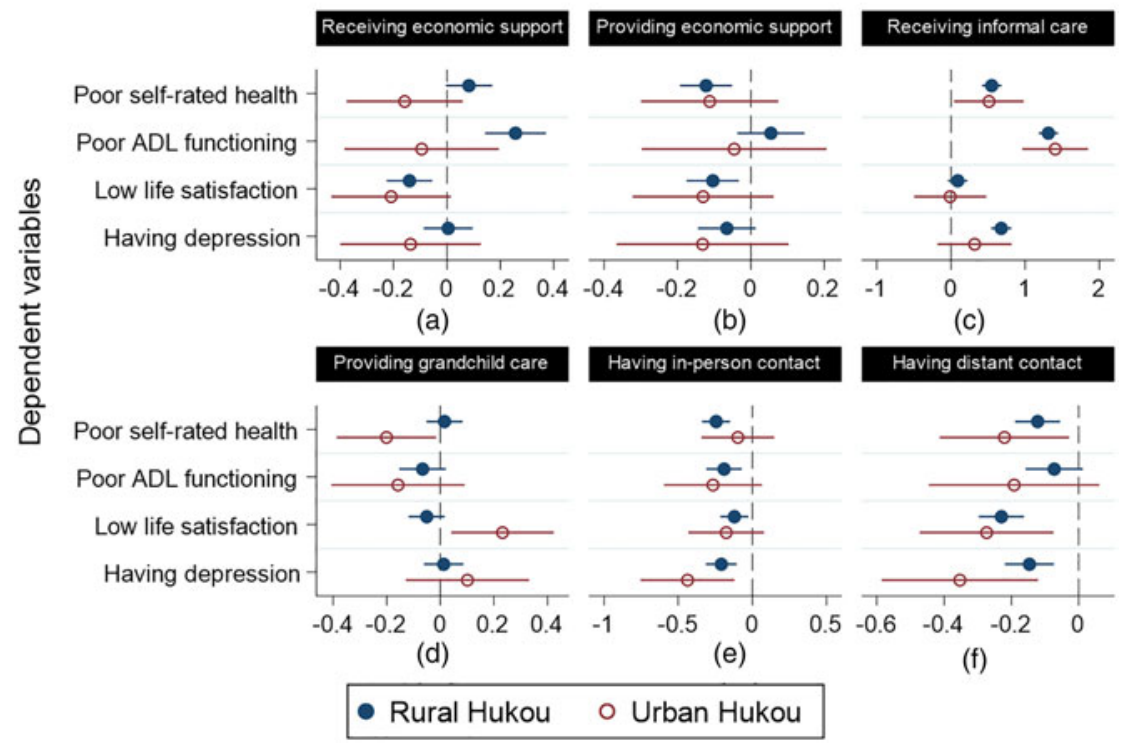

Figure 4. Influence of the exchange of intergenerational support on the health status of older people in rural and urban areas (2011, 2013 and 2015).

Note: Independent variables include intergenerational support/contact; dependent variables include physical and psychological health outcomes; covariates such as the age, gender, marital status, educational attainment, whether currently working, co-residing with at least one adult child, individual income, the number of chronic illnesses and children were included in the models, the results of which were significant but omitted in the figure for the clarity of result visualisation. ADL: activities of daily living.

Source: Authors' analysis of the China Health and Retirement Longitudinal Study (CHARLS) data.

In addition, the odds of having poor self-rated health and low life satisfaction reduced for older people who provided economic support to their adult children/ grandchildren in rural areas, which indicates that the provision of economic support to adult children contributes to a positive effect on older people's self-rated health and life satisfaction in rural areas (see Figure 4b). However, the provision of downward economic support did not show any significant association with the health status of older people in urban areas. The results suggest that the health of older people in rural areas is more likely to be influenced by the exchange of economic support, which may be due to the fact that respondents in rural areas have fewer economic resources, and are more economically dependent compared to their urban counterparts (Ma et al., 2011; Luo et al., 2017).

For older people in rural areas, the odds of reporting poor self-rated health were higher among respondents who received informal care from their adult children compared to those who did not receive such support (see Figure 4c). Moreover, receiving informal care from one's adult children was associated with a poor ADL functional status and reporting depressive symptoms among older people in rural areas. Similar associations between receiving informal care and self-rated health/ADL functioning were also found among older people in urban areas. 
This could be explained by the fact that receiving informal care is often associated with the loss of independence and deterioration in one's health condition, which will be further discussed later (Lee et al., 1994; Schwarz et al., 2010).

The provision of grandchild care did not have significant associations with older people's health status in rural areas. However, this was associated with a reduction in the odds of reporting poor self-rated health, and an increase in the odds of having a low life satisfaction among older people in urban areas (see Figure 4d). Overall, grandchild care provision was a stronger predictor for the health of older people in urban areas compared to those in rural areas. As found by a recent study, providing care to grandchildren can result in feelings of pressure and a low life satisfaction among older people (Kim et al., 2017). Hence, the health risks relating to caring for grandchildren should be prioritised by the community and carer groups, which is discussed further in the next section.

Having weekly in-person contact with one's adult children was positively associated with older people's self-rated health, ADL functional status, life satisfaction and depression in rural areas (see Figure 4e). For example, respondents who had weekly in-person contact with their adult children were less likely to report poor self-rated health compared to their counterparts with no such contact. In addition, having weekly in-person contact was protective for the depression status of older people in urban areas. Meanwhile, having distant contact with adult children improved older people's self-rated health and life satisfaction, and reduced their risk of having depression in both rural and urban areas (see Figure 4f).

The current study also found significant gender differences in the relationships between intergenerational support exchanges and health among older people. For example, compared to male respondents, female respondents were more likely to receive help with ADLs and IADLs from their adult children in both rural and urban areas, and were more likely to have weekly in-person contact with their adult children in urban areas (see Table S2 in the online supplementary material). Female respondents had higher odds of reporting poor self-rated health compared to their male counterparts, in both rural and urban areas (see Table S2 in the online supplementary material). In addition, female respondents were more likely to have poor ADL functional status than their male counterparts in rural areas, and were more likely to report depressive symptoms compared to their male counterparts in urban areas.

\section{Discussion and conclusion}

This current study represents a unique contribution to existing literature by focusing not only on the differences in the exchange of intergenerational support between rural and urban families, but also on how such patterns are differently associated with health status among older people in rural and urban areas, represented by both physical and psychological dimensions. Understanding such relationships is critical considering the irreplaceable role of intergenerational support within Chinese families (Lin and Yi, 2011).

The study makes a number of contributions, which are original considering the complexity of the analysis. The first important finding is that older people in both rural and urban areas were less likely than before to live together with their adult 
children, which was associated with a reduction in the receipt of informal care and weekly in-person contact with their adult children. This finding is in line with part of the modernisation and ageing theory, showing that increasing intergenerational living distance can largely prohibit the process of informal care provided from adult children to their older parents (e.g. Silverstein et al., 2006; Guo et al., 2009; Lin and Yi, 2011). The results are consistent with a recent study by Gruijters (2017), showing the reduction in having intergenerational in-person contact was largely due to the massive rural to urban migration and increased intergenerational geographical distance in China. In addition, older people in both rural and urban regions were less likely to have in-person or distant contact with their adult children compared to in 2011. However, not living nearby one's adult child was associated with an increase in having intergenerational weekly distant contact in both rural and urban areas, which is in line with the modified extended family model.

Reflecting the complexity of the associations under study, receiving informal care from one's adult children was associated with poorer ADL/IADL functional status and depression status among older people in rural areas, while having weekly in-person and distant contact reduced the risk of depression among older people in both rural and urban areas. The findings build on a recent cross-sectional study by Luo et al. (2017), who found that having contact with one's adult children was associated with an improvement in depression status among older people in rural areas, and add to our understanding of such relationships in urban areas. This current study also revealed that in rural areas, older people's poor $\mathrm{ADL} / \mathrm{IADL}$ functional status and depressive symptoms could partially result from the receipt of informal care from one's adult children. The findings support the earlier observations that a more frequent receipt of social support is associated with an increased risk of ADL limitations (among men) (Seeman et al., 1996). The declined depression status could be explained by the loss of independence among older people who received social support from their adult children, which suggests that self-reliance and autonomy might play a more important role among Chinese older people nowadays (Schwarz et al., 2010).

A second key finding of this paper relates to older people in rural areas being more dependent on their adult children for economic support compared to their urban counterparts. Specifically, a high proportion of older people in rural areas received economic support from their adult children (78\% in 2013 and $86 \%$ in 2015), which was associated with their high life satisfaction. This provides evidence for the social exchange theory, and indicates that older people in rural areas are likely to have a lower life satisfaction if they lack economic transfers from their adult children (Chen and Jordan, 2018). Moreover, not living together with one's adult child was associated was an increase in economic support exchange, which supports the economics of labour migration theory (Stark and Bloom, 1985). The findings extend the work of Liang and $\mathrm{Wu}$ (2014), who found that about half of the older people in empty-nest households in rural China reported low levels of life satisfaction and hypothesised that this was associated with the reduction in economic support provided by adult children (Liang and $\mathrm{Wu}, 2014$ ). This current study provides empirical evidence in support of such a hypothesis with a direct examination of the two variables.

Compared to this, the health status of older people in urban areas was more likely to be negatively impacted by the provision of grandchild care compared to their 
counterparts in rural areas. This study has found that about half of the respondents took care of their grandchildren, and this proportion was higher for respondents in urban areas compared to those in rural areas. This is consistent with previous studies showing that older people are important care providers for their grandchildren (e.g. Croll, 2008; Liu, 2014). Our analysis went a step further showing (in Figure 4d) that the provision of grandchild care was not significantly associated with the health of older people in rural areas, while it had a negative effect on life satisfaction among older people in urban areas, which does not support the esteem enhancement theory. Some research has shown that the provision of grandchild care may present certain health challenges for older people (Kim et al., 2017; Zhou et al., 2018). On the one hand, recent studies have indicated that older people and adult children have conflicts about understandings of child rearing. Older people often feel unvalued and disrespected from such conflicts, which can result in poor psychological health outcomes among them (Kim et al., 2017). On the other hand, older people may suffer from the burden of household chores, grandchild care and communication problems (Zhou et al. 2018). The stress resulting from caring for grandchildren could increase if people retire at an older age once the reform to increase the pension age is implemented in China (Falkingham et al., 2020).

It is important to note that significant gender differences were found in the relationships between intergenerational support exchanges and health among older people. Consistent with previous research, the current study found that compared to older men, older women were more likely to receive informal care and have regular contact with their adult children (Zhang et al., 2005; Hu and Ma, 2018). This study also provided supportive evidence to existing research on the poorer self-rated health among female respondents than their male counterparts, in both rural and urban areas (Li et al., 2009). In addition, the analysis suggested a higher risk of poorer ADL functional status and of depression among female respondents compared to their male counterparts. The results were consistent with previous studies showing older women's poorer ADL performance and higher levels of depressive symptoms compared to men (Zhang et al., 2005; Chao, 2011).

Finally, this current study has found that having weekly in-person and distant contact was protective in terms of the depression status of older people in both rural and urban areas. This finding is in accordance with previous studies which have demonstrated that having frequent intergenerational contact has a positive protective effect in terms of older people's emotional wellbeing (including depression status) (Li et al., 2014). Furthermore, it also corroborates the findings of previous work by Leung et al. (2007), who found that maintaining intergenerational ties was beneficial for older people's depressive symptoms, and activities such as having frequent contact played a more significant role than receiving upward social support in such impact. As shown in this current study, the out-migration of adult children has made it challenging for older people to maintain frequent in-person contact with their children. One the one hand, it is crucial for the Chinese government to realise the importance of strengthening intergenerational in-person contact (Luo et al., 2017). On the other hand, with the research findings from this study in mind, a more realistic way would be to encourage adult children to contact their older parents via phone/mail/email more often, since having frequent distant contact with one's adult children is also beneficial for older people's psychological health. 


\section{Policy and practice implications}

The findings of this study have implications for policy and practice. The analysis has augmented the evidence for great diversity between rural and urban areas in older persons' socio-demographic characteristics, including their family structure, average educational attainment and economic activities, and different receipt/provision levels of intergenerational economic, social and psychological support (e.g. Young, 2013; Luo et al., 2017). It is therefore recommended to plan the health and social care for rural and urban older residents separately, as a unified welfare policy may have different impacts on the net welfare of older people in rural and urban areas (Jiang et al., 2013; Ning and Wang, 2015). For instance, communitybased care services have been successfully provided in some urban areas of China, while these are unavailable in the majority of rural areas. Compared to delivering services by day care centres or nursing institutions, shared care from neighbours and villagers may be more realistic within a rural community (Zhu and Walker, 2018). Furthermore, it is important to improve the level of pensions/public economic transfers and public social care for rural Chinese older people, so that they can be less dependent on the economic support provided by their adult children (Ning and Wang, 2015). For urban older residents who live in better economic conditions, policy makers should put more emphasis on improving their psychological wellbeing, such as the diagnosis of depression (Luo et al., 2017).

It is also crucial for the Chinese government to realise the importance of enhancing traditional filial values in various ways (Luo et al., 2017). In addition to encouraging adult children to visit their parents more regularly and including such recommendations in the law, the Chinese government raised 'Twenty-four Rules for Being a Filial Person in Contemporary China' (The All-China Women's Federation, 2012). The rules include specific items such as 'teaching parents to use the Internet and go online surfing', 'contacting parents via phone/internet', 'travelling', 'working out together' and 'taking them to conduct health examinations regularly' (The All-China Women's Federation, 2012). Despite being criticised as being unrealistic and ambitious, the rules have provided an updated understanding of filial piety in China and expressed a solid attitude towards enhancing intergenerational ties by the Chinese government. As a matter of fact, various forms of intergenerational support are gradually being accepted by older people in China, especially taking into consideration the rapid societal development in China (Luo and Zhan, 2012). Yet, it is important to understand how such transformations in intergenerational contact may affect older people's health status, thus further recommendations can be provided based on the evidence.

Another recommendation is that social policy makers and practitioners should pay close attention to the health and wellbeing of grandparents, especially those with intensive grandchild care commitments (Baker and Silverstein, 2012; Di Gessa et al., 2016). For instance, formal child-care provision programmes can be designed to support older people providing supplementary grandchild care (Kim et al., 2017).

This study has a number of limitations which are important to take into account when interpreting the findings. First, the changes in the flows of intergenerational economic, social and psychological support cannot be examined over a prolonged 
period, as this study can only obtain the data over a five-year period due to the availability of the CHARLS. As such, it is conceivable that the patterns of support described in this paper are unique to the period under study. Despite this, other studies have found similar patterns of intergenerational support during the same period (i.e. Gruijters, 2017), which supports the findings of this study. Second, this current study excludes nearly 40 per cent of the original sample, as these respondents did not have valid information about support exchange with their adult children. Chi-square tests have been conducted to examine if any pattern or specific characteristics define the deleted sample, and no significant differences were found between the analytical sample and the deleted sample (Chen, 2014). Finally, due to the relatively small sample of urban residents in this study $(\mathrm{N}=$ 798), the effects of intergenerational support exchange on the older people's health were not examined by gender respectively.

Notwithstanding these limitations, this paper makes theoretical and empirical contributions to the research on intergenerational support exchange in China. The theoretical contribution of this study is that it provides supportive evidence for the economics of labour migration theory, the modified extended family model and the social exchange theory, but not for the esteem enhancement theory (Greenwell and Bengtson, 1997; Stark and Bloom, 1985; Chen and Jordan, 2018). A part of the modernisation and ageing theory, which emphasises family separation and a reduction in receiving informal care by older people, is also supported by the study findings. Empirically, this study contributes to our understanding of the intergenerational support exchanges within rural and urban Chinese families, in three unique ways. Firstly, in reviewing the literature, there has been scarce research examining different types/directions of intergenerational support thoroughly in a single study (Peng et al., 2019). This study marks the first comprehensive attempt to investigate the flows of intergenerational economic, social and psychological support bi-directionally. Secondly, this study analyses the exchange of intergenerational support with a focus on rural and urban disparities, which is an increasingly important aspect of intergenerational support patterns (Zimmer and Kwong, 2003; Gruijters, 2017; Luo et al., 2017). Finally, the impact of the receipt or provision of intergenerational support on older people's physical health status has been rarely discussed in the existing literature. This study provides additional evidence for understanding the association between intergenerational support exchanges and the ADL/IADL functional status of older people. Taking account of the contextual factors such as rapid ageing, massive migration and substantial rural-urban differences in contemporary China, this study provides empirical evidence for our understanding of changing intergenerational support in rural and urban regions separately, which is crucial to both practitioners and policy makers.

Supplementary material. The supplementary material for this article can be found at https://doi.org/10. 1017/S0144686X21000702

Financial support. This work was supported by the Economic and Social Research Council Post-Doctoral Fellowship (grant number ES/V011456/1); the Economic and Social Research Council Doctoral Training Centre (grant number ES/J500161/1); and National Social Science Foundation Youth Project (grant number 20CSH014). Researchers are independent of sponsors. 
Ethical standards. This study was approved by the University of Southampton's Ethics Committee.

\section{Notes}

1 The economic support received and provided by the respondents included both their and their partner's finances. This is because much of the joint expenditure by older parents was indistinguishable, therefore it is helpful to consider the respondents and their spouse at an aggregate level for these variables (Silverstein et al., 2006). However, respondents who did not have a spouse were also asked the same question, and their answers only referred to their own support exchange patterns. Meanwhile, economic support provided to/ from adult children and grandchildren was measured at an aggregate level, due to the prevalence of having three-generation families compared to having only two generations of kin in China (Lei et al., 2015).

2 Age was treated as a time-invariant variable, as it is perfectly correlated with time in a panel study (Sheng and Killian, 2009).

\section{References}

Aboderin I (2004) Modernisation and ageing theory revisited: current explanations of recent developing world and historical Western shifts in material family support for older people. Ageing \& Society 24, 29-50.

Allison PD (2009) Fixed Effects Regression Models. New York, NY: Sage.

Ao X, Jiang DW and Zhao Z (2016) The impact of rural-urban migration on the health of the left-behind parents. China Economic Review 37, 126-139.

Baker L and Silverstein M (2012) The well-being of grandparents caring for grandchildren in China and the United States. In Arber S and Timonen V (eds), Contemporary Grandparenting: Changing Family Relationships in Global Contexts. Bristol, UK: Policy Press, pp. 50-70.

Batson CD and Powell AA (1998) Altruism and prosocial behavior. In Fiske ST, Gilbert DT and Lindzey G (eds), Handbook of Social Psychology. New York, NY: McGraw-Hill, pp. 463-484.

Beaumaster S, Chien S, Lau S, Lin A, Phillps D, Wilkens J and Lee J (2018) Harmonised CHARLS Documentation. Beijing: Peking University. Available at http://charls.pku.edu.cn/uploads/document/harmonized_charls/application/Harmonized_CHARLS_C.pdf.

Bengtson V, Giarrusso R, Mabry JB and Silverstein M (2002) Solidarity, conflict, and ambivalence: complementary or competing perspectives on intergenerational relationships? Journal of Marriage and Family 64, 568-576.

Blau P (1964) Exchange and Power in Social Life. New York, NY: Wiley.

Chao SF (2011) Assessing social support and depressive symptoms in older Chinese adults: a longitudinal perspective. Aging and Mental Health 15, 765-774.

Chen Q (2014) Advanced Econometrics and Stata Applications. Beijing: Higher Education Press. (In Chinese)

Chen J and Jordan LP (2018) Intergenerational support and life satisfaction of young-, old- and oldest-old adults in China. Aging and Mental Health 22, 412-420.

Chen X and Silverstein M (2000) Intergenerational social support and the psychological well-being of older parents in China. Research on Aging 22, 43-65.

Chen G, Liu J, Xu J and Shu X (2005) Analysis on intergenerational economics transfers in Chinese families. Market and Demographic Analysis 5, 18-23. (In Chinese)

Chen F, Liu G and Mair CA (2011) Intergenerational ties in context: grandparents caring for grandchildren in China. Social Forces 90, 571-594.

Chen F, Lucas H, Bloom G and Ding S (2016) Household structure, left-behind elderly, and rural migration in China. Journal of Agricultural and Applied Economics 48, 279-297.

Cheng ST and Chan AC (2008) Filial piety and psychological well-being in well older Chinese. Journals of Gerontology: Psychological Sciences and Social Sciences 61B, 262-269.

Chien S, Lin A, Phillps D, Wilkens J and Lee J (2017) Harmonized CHARLS Documentation. Beijing: Peking University. Available at http://charls.pku.edu.cn/uploads/document/harmonized_charls/application/Harmonized_CHARLS_B.4.pdf.

China Health and Retirement Longitudinal Study (CHARLS) (2015) China Health and Retirement Longitudinal Study Followup 2013 Release Note. Beijing: Peking University. Available at http://charls. pku.edu.cn/uploads/document/charls2013-wave2/application/Release_note.pdf. 
Chou KL and Chi I (2000) Comparison between elderly Chinese living alone and those living with others. Journal of Gerontological Social Work 33, 51-66.

Cong $\mathbf{Z}$ and Silverstein $\mathbf{M}$ (2011) Intergenerational exchange between parents and migrant and nonmigrant sons in rural China. Journal of Marriage and Family 73, 93-104.

Cowgill DO (1972) A theory of aging in cross-cultural perspective. In Cowgill DO and Holmes LD (eds), Aging and Modernization. New York, NY: Appleton-Century-Crofts, pp. 1-14.

Croezen S, Avendano M, Burdorf A and Van Lenthe FJ (2015) Social participation and depression in old age: a fixed-effects analysis in 10 European countries. American Journal of Epidemiology 182, 168-176.

Croll EJ (2008) The intergenerational contract in the changing Asian family. In Goodman H (ed.), Ageing in Asia. London: Routledge, pp. 100-118.

Di Gessa G, Glaser K and Tinker A (2016) The impact of caring for grandchildren on the health of grandparents in Europe: a lifecourse approach. Social Science and Medicine 152, 166-175.

Diggle P (2002) Analysis of Longitudinal Data. Oxford: Oxford University Press.

Du P and Wu C (2006) Changes of main income sources of Chinese older people in 1994-2004. Population Research 30, 20-24. (In Chinese)

Falkingham J, Evandrou M, Qin M and Vlachantoni A (2020) Informal care provision across multiple generations in China. Ageing \& Society 40, 1978-2005.

Foster AD and Rosenzweig MR (2001) Imperfect commitment, altruism, and the family evidence from transfer behavior in low-income rural areas. Review of Economics and Statistics 83, 389-407.

Giles J and Mu R (2007) Elderly parent health and the migration decisions of adult children: evidence from rural China. Demography 44, 265-288.

Giles J, Wang D and Zhao C (2010) Can China's rural elderly count on support from adult children? Implications of rural-to-urban migration. Journal of Population Ageing 3, 183-204.

Graf C (2008) The Lawton instrumental activities of daily living scale. American Journal of Nursing 108, $52-62$.

Graham E, Jordan LP and Yeoh BS (2015) Parental migration and the mental health of those who stay behind to care for children in South-East Asia. Social Science and Medicine 132, 225-235.

Greenwell L and Bengtson VL (1997) Geographic distance and contact between middle-aged children and their parents: the effects of social class over 20 years. Journals of Gerontology: Psychological Sciences and Social Sciences 52B, S13-S26.

Gruenewald TL and Seeman TE (2011) Social support and physical health: links and mechanisms. In Steptoe A, Freedland K, Jennings JR, Llabre MM, Manuck SB and Susman EJ (eds), Handbook of Behavioral Medicine: Methods and Applications. New York, NY: Springer Science + Business Media, pp. 225-236.

Gruijters RJ (2017) Intergenerational contact in Chinese families: structural and cultural explanations. Journal of Marriage and Family 79, 758-768.

Guo M, Chi I and Silverstein M (2009) Intergenerational support of Chinese rural elders with migrant children: do sons' or daughters' migrations make a difference? Journal of Gerontological Social Work 52, 534-554.

Hank K (2007) Proximity and contacts between older parents and their children: a European comparison. Journal of Marriage and Family 69, 157-173.

Hartigan I (2007) A comparative review of the Katz ADL and the Barthel Index in assessing the activities of daily living of older people. International Journal of Older People Nursing 2, 204-212.

Hu B and Ma S (2018) Receipt of informal care in the Chinese older population. Ageing \& Society 38, 766-793.

Huang B, Lian Y and Li W (2016) How far is Chinese left-behind parents' health left behind? China Economic Review 37, 15-26.

Jiang K, Pei Y and Xia C (2013) The patterns and motivations of intergenerational transfers in China: evidence based on CHARLS data. Economic Review 4, 37-46. (In Chinese)

Katz S, Ford AB, Moskowitz RW, Jackson BA and Jaffe MW (1963) Studies of illness in the aged: the index of ADL: a standardized measure of biological and psychosocial function. JAMA: The Journal of the American Medical Association 185, 914-919.

Kim HJ, Kang H and Johnson-Motoyama M (2017) The psychological well-being of grandparents who provide supplementary grandchild care: a systematic review. Journal of Family Studies 23, 118-141.

Lawton MP and Brody EM (1969) Assessment of older people: self-maintaining and instrumental activities of daily living. The Gerontologist 9, 179-186. 
Lee YJ, Parish WL and Willis RJ (1994) Sons, daughters, and intergenerational support in Taiwan. American Journal of Sociology 99, 1010-1041.

Lei X, Strauss J, Tian M and Zhao Y (2015) Living arrangements of the elderly in China: evidence from the CHARLS national baseline. China Economic Journal 8, 191-214.

Leung KK, Chen CY, Lue BH and Hsu ST (2007) Social support and family functioning on psychological symptoms in elderly Chinese. Archives of Gerontology and Geriatrics 44, 203-213.

Li S, Song L and Feldman MW (2009) Intergenerational support and subjective health of older people in rural China: a gender-based longitudinal study. Australasian Journal on Ageing 28, 81-86.

Li H, Ji Y and Chen T (2014) The roles of different sources of social support on emotional well-being among Chinese elderly. PLOS ONE 9, e90051.

Liang Y and Wu W (2014) Exploratory analysis of health-related quality of life among the empty-nest elderly in rural China: an empirical study in three economically developed cities in eastern China. Health and Quality of Life Outcomes 12, 1-16.

Lin JP and Yi CC (2011) Filial norms and intergenerational support to aging parents in China and Taiwan. International Journal of Social Welfare 20, S109-S120. (In Chinese)

Litwak E (1960) Geographic mobility and extended family cohesion. American Sociological Review 25, 385-394.

Liu J (2014) Ageing, migration and familial support in rural China. Geoforum 51, 305-312.

Liu Y and Zhang J (2017) Does informal care imrove older people's psychological health? An empirical study based on the CHARLS 2013. South China Population 32, 64-78.

Luo B and Zhan H (2012) Filial piety and functional support: understanding intergenerational solidarity among families with migrated children in rural China. Ageing International 37, 69-92.

Luo H, Wu K, Qian J, Cao P and Ren X (2017) Urban-rural differences in the role of family support in physical and mental health of older people in China. Journal of Sichuan University (Medical Science Edition) 48, 263-267. (In Chinese)

Ma C, Shi J, Li Y, Wang Z and Tang C (2011) The trend and recent findings in the change of families in urban China. Sociological Research 2, 182-216.

Ministry of Civil Affairs (2018) Statistical Bulletin of Social Development in China, 2017. Beijing: Ministry of Civil Affairs. Available at http://www.mca.gov.cn/article/sj/tjgb/2017/201708021607.pdf. (In Chinese)

National Bureau of Statistics of the People's Republic of China (NBS) (2002) The Fifth Census in China, 2000. Beijing: NBS. Available at http://www.stats.gov.cn/tjsj/pcsj/rkpc/5rp/index.htm.

National Bureau of Statistics of the People's Republic of China (NBS) (2019) Population Structure and Dependency Ratio of the Chinese Population, 2018. Beijing: NBS. Available at http://data.stats.gov.cn/ easyquery.htm? $\mathrm{cn}=\mathrm{C} 01$.

Ni Y, Tein JY, Zhang M, Yang Y and Wu G (2017) Changes in depression among older adults in China: a latent transition analysis. Journal of Affective Disorders 209, 3-9.

Ning $\mathbf{M}$ and Wang $\mathbf{X}$ (2015) The motivations of intergenerational transfers in rural China. Agricultural Technology Enocomics 5, 21-33. (In Chinese)

Oliveira J (2016) The value of children: inter-generational support, fertility, and human capital. Journal of Development Economics 120, 1-16.

Oxman TE and Hull JG (1997) Social support, depression, and activities of daily living in older heart surgery patients. Journals of Gerontology: Psychological Sciences and Social Sciences 52B, P1-P14.

Peng C, Kwok CL, Law YW, Yip PS and Cheng Q (2019) Intergenerational support, satisfaction with parent-child relationship and elderly parents' life satisfaction in Hong Kong. Aging and Mental Health 23, 428-438.

Qiu J, Wang Z and Wen Y (2013) The impact of the urban-rural difference on individual's income: a study based on CGSS 2008. West Forum on Economy and Management 24, 74-81.

Rabe-Hesketh S and Skrondal A (2008) Multilevel and Longitudinal Modeling Using Stata. College Station, TX: Stata Press.

Radloff LS (1977) The CES-D Scale: a self-report depression scale for research in the general population. Applied Psychological Measurement 1, 385-401.

Ren Q and Treiman DJ (2015) Living arrangements of the elderly in China and consequences for their emotional well-being. Chinese Sociological Review 47, 255-286.

Schunck R (2013) Within and between estimates in random-effects models: advantages and drawbacks of correlated random effects and hybrid models. Stata Journal 13, 65-76. 
Schwarz B, Trommsdorff G, Zheng G and Shi S (2010) Reciprocity in intergenerational support: a comparison of Chinese and German adult daughters. Journal of Family Issues 31, 234-256.

Seeman TE, Bruce ML and McAvay GJ (1996) Social network characteristics and onset of ADL disability: MacArthur studies of successful aging. Journals of Gerontology: Psychological Sciences and Social Sciences 51B, S191-S200.

Sheng X and Killian TS (2009) Over time dynamics of monetary intergenerational exchanges. Journal of Family and Economic Issues 30, 268-281.

Silverstein M, Cong $\mathbf{Z}$ and Li S (2006) Intergenerational transfers and living arrangements of older people in rural China: consequences for psychological well-being. Journals of Gerontology: Psychological Sciences and Social Sciences 61B, S256-S266.

Stark O and Bloom DE (1985) The new economics of labor migration. American Economic Review 75, 173-178.

StataCorp (2019) Stata Statistical Software: Release 16. College Station, TX: StataCorp.

Tang $\mathbf{S}$ and Feng $\mathbf{J}$ (2015) Cohort differences in the urban settlement intentions of rural migrants: a case study in Jiangsu Province, China. Habitat International 49, 357-365.

Taylor JE, Rozelle S and De Brauw A (2003) Migration and incomes in source communities: a new economics of migration perspective from China. Economic Development and Cultural Change 52, 75-101.

The All-China Women's Federation (2012) Twenty-four Rules for Being a Filial Person in Contemporary China. Beijing: Wenchang Women. Available at http://www.wenchangwomen.gov.cn/show-37-103-1. html. (In Chinese)

The Statistics Portal (2015) Average Number of People Living in Households in China from 1990 to 2014. New York, NY: Statista. Available at https://www.statista.com/statistics/278697/average-size-of-households-in-china/.

Wang Y and Chen Q (2017) The impact of pension income on rural families' intergenerational transfers. Financial Economics Research 32, 117-128. (In Chinese)

Xie Y and Zhu H (2009) Do sons or daughters give more money to parents in urban China? Journal of Marriage and Family 71, 174-186.

Yang L, Martikainen P, Silventoinen K and Konttinen H (2016) Association of socioeconomic status and cognitive functioning change among elderly Chinese people. Age and Ageing 45, 674-680.

Young J (2013) China's Hukou System. Basingstoke, UK: Palgrave Macmillan.

Zeng Y (1986) Changes in family structure in China: a simulation study. Population and Development Review 12, 675-703.

Zhang W, Li S and Feldman MW (2005) Gender differences in activity of daily living of the elderly in rural China: evidence from Chaohu. Journal of Women and Aging 17, 73-89.

Zhang Z, Gu D and Luo Y (2014) Coresidence with elderly parents in contemporary China: the role of filial piety, reciprocity, socioeconomic resources, and parental needs. Journal of Cross-cultural Gerontology 29, 259-276.

Zheng $\mathbf{Z}$ and Zheng $\mathbf{Y}$ (2017) The influence of social support on the health and life satisfaction of the older people: a re-examination based on the endogeneity of intergenerational economic support. Population and Economics 4, 63-76. (In Chinese)

Zhou Z, Mao F, Ma J, Hao S, Qian Z, Elder K, Turner JS and Fang Y (2018) A longitudinal analysis of the association between living arrangements and health among older adults in China. Research on Aging 40, 72-97.

Zhu H and Walker A (2018) The gap in social care provision for older people in China. Asian Social Work and Policy Review 12, 17-28.

Zimmer Z and Kwong J (2003) Family size and support of older adults in urban and rural China: current effects and future implications. Demography 40, 23-44.

Cite this article: Yang Y, Evandrou M, Vlachantoni A (2023). The impact of living arrangements and intergenerational support on the health status of older people in China: are rural residents disadvantaged compared to urban residents? Ageing \& Society 43, 469-494. https://doi.org/10.1017/S0144686X21000702 